\title{
APONTAMENTOS SOBRE A VIOLÊNCIA CONTRA A MULHER NA POLÍTICA INSTITUCIONAL BRASILEIRA ${ }^{1}$
}

\author{
STATEMENTS ON VIOLENCE AGAINST WOMEN IN BRAZILIAN \\ INSTITUTIONAL POLITICS
}

\author{
Juliene Tenório de Albuquerque ${ }^{2}$ \\ Elba Ravane Alves ${ }^{3}$
}

\begin{abstract}
RESUMO
O presente artigo tem como objeto de estudo a violência contra mulher na arena política e foi desenvolvido um estudo bibliográfico a partir de referenciais teóricos de Pierre Bourdieu, Heleieth Saffioti, Flávia Biroli e Luis Felipe Miguel. A pesquisa qualitativa teve como objetivo geral analisar a violência contra mulher na arena política no Brasil. Também lançamos mão de tipos descritivos, exploratórios e explicativos em nosso estudo, considerando as inferências descritivas que realizamos a partir de casos concretos de violência contra mulheres nas instituições políticas. A dimensão exploratória ocorre com a exploração de um fenômeno ainda pouco investigado no Brasil e a dimensão explicativa se dá nas inferências causais entre a violência política contra a mulher e a sub-representação política desse segmento (LOPES, 2006). Para a coleta de dados, utilizamos a técnica da pesquisa documental a partir de documentos escritos e audiovisuais. São objetivos específicos identificar ocorrências de violência contra a mulher no Brasil; Refletir a ausência de marcos legais para o enfrentamento a esse tipo de violência e debater a relação entre a violência contra mulher na arena política e a baixa representatividade das mulheres nos espaços de poder. Chegamos aos seguintes achados: A) uma das formas de expressão da dominação masculina é a violência contra as mulheres no campo político, a violência contra mulher na arena política é uma variável que contribui para a baixa presença das mulheres nos espaços políticos; B) no Brasil, esse fenômeno é ainda invísivel nos espaços institucionais dos poderes públicos e pouco debatido na academia e nos movimentos socais; C) Na pesquisa documental identificamos a ocorrências de violência contra a mulher no Brasil o que restou constatado através dos casos envolvendo a Presidenta da República deposta do cargo Dilma Rousseff, as Deputadas Federais Maria do Rosário e Jandira Feghali, da Deputada Estadual Manuela D’ávila e da Vereadora Marília Arraes. D) Não idenficou-se no Brasil marcos legais, projetos de lei e nem experiências de políticas públicas que tenham como objeto o enfrentamento a violência contra mulher na arena política.
\end{abstract}

Palavras-Chaves: Democracia; Gênero; Violência política.

\footnotetext{
1 Agradecemos as contribuições para a presente pesquisa do ativista LGBT e Pesquisador Cleyton Feitosa, doutorando em Ciências Políticas pela UNB

2 Possui graduação em Serviço Social (2003), Mestrado em Serviço Social (2008) e Doutorado em Serviço Social (2014) pela Universidade Federal de Pernambuco (UFPE), tendo desenvolvido pesquisas sobre Juventude(s) e Políticas Públicas de Juventude(s). Atualmente é docente do curso de Serviço Social da UNINABUCO Recife.

${ }^{3}$ Mestra em Direitos Humanos pela UFPE, Advogada, Especialista em Segurança Pública e Cidadania pela ASCES, professora universitária da ASCES UNITA da graduação em Direito, Administração Pública, Serviço Social, nas áreas de Gênero e Relações de Família, Direitos Humanos e Direito das Coisas. Atualmente Coordenadora da ONG Diversa: Centro de Pesquisa em Direitos Humanos, Gênero e Democracia
} 


\title{
sorista \\ Debates Insubmissos
}

\begin{abstract}
This article aims to study violence against women in the political arena and a bibliographical study was developed from the theoretical references of Pierre Bourdieu, Heleieth Saffioti, Flávia Biroli and Luis Felipe Miguel. Qualitative research aimed to analyze violence against women in the political arena in Brazil. We also use descriptive, exploratory and explanatory types in our study, considering the descriptive inferences that we make from concrete cases of violence against women in political institutions. The exploratory dimension occurs with the exploration of a phenomenon still little investigated in Brazil and the explanatory dimension occurs in the causal inferences between political violence against women and the political under-representation of this segment (LOPES, 2006). For the collection of data, we use the technique of documentary research from written and audiovisual documents. Specific objectives are to identify occurrences of violence against women in Brazil; Reflect the absence of legal frameworks to address this type of violence and discuss the relationship between violence against women in the political arena and the low representation of women in power spaces. We come to the following findings: A) one of the forms of expression of male domination is violence against women in the political field, violence against women in the political arena is a variable that contributes to the low presence of women in political spaces; B) in Brazil, this phenomenon is still invisible in the institutional spaces of the public powers and little debated in the academy and social movements; $C$ ) In the documentary research we identified the occurrences of violence against women in Brazil, which was verified through the cases involving the President of the Republic deposed Dilma Rousseff, Federal Mothers Maria do Rosário and Jandira Feghali, State Representative Manuela D'ávila and Vitoria Marília Arraes. D) In Brazil legal frameworks, bills and public policy experiences have not been identified in order to combat violence against women in the political arena.
\end{abstract}

Keywords: Democracy; Gender; Political violence.

\section{INTRODUÇÃO}

A desigualdade de gênero é um fenômeno que historicamente tem submetido as mulheres a processos de silenciamento. O silenciamento pode ser considerado violência estrutural que na sociedade demarcada por desigualdades é naturalizada, banalizada e invisibilizada, resultando, assim, na perpetuação de violências físicas, psicológicas e sexuais nos espaços públicos e privados.

Na sociedade erguida a partir da Ordem Patriarcal de Gênero, à mulher é ensinado desde cedo que não deve preocupar-se em aprender a se comunicar, a se expressar e a se apropriar das regras e dinâmicas do jogo político. Deve preocupar-se tão somente em apreender as prendas domésticas, visto que assim, cumprirá com o papel social que lhe é atribuído, e assim, consoante Saffioti assinala (2013), às mulheres de determinadas regiões do 
Brasil não era ensinado sequer a língua portuguesa, colocando-as no isolamento social dentro e fora de casa a partir da exclusão educacional.

Ao longo da história, vários estudos vão tentar conferir visibilidade à condição sociopolítica das mulheres, mas é quando gênero se torna uma categoria de análise que os estudos ganham maior inserção nos espaços de produção do conhecimento e se tornam uma tradição científica amplamente difundida e consolidada (SCOTT, 1989).

A análise da desigualdade entre homens e mulheres na vida social e, mais especificamente, na política institucional, contribui para compreender a relação com a negação de direitos.

Ao longo da história construiu-se teoricamente teses que deram sustentação ao poderio dos homens. Ao analisar epistemologicamente tais construções teóricas a partir de uma observação atenta das relações de gênero, Matos e Paradis (2014) apontam que John Locke considerava os homens seres racionais por excelência. Assim, ao homem foi concebido o poder de participar da esfera pública (e, portanto, das decisões que afetavam a todos), de maneira igualitária e livre. As mulheres, em contrapartida, eram consideradas carentes de razão e assim deveriam permanecer no lugar que lhes seria "natural": a esfera privada. Observamos que tais construções teóricas e filosóficas deram sustentação retórica à negação dos direitos políticos das mulheres, valendo-se o poder do homem de diversos mecanismo para exclusão das mulheres desse campo político, consideramos a violência contra mulher na arena política um desses mecanismos de exclusão da mulher dos espaços de poder, negandolhes o exercício pleno dos direitos políticos.

Com base nesse diagnóstico prévio, tomamos como questões-problema as seguintes indagações: de que modo a violência contra a mulher se expressa na política institucional? Quais os efeitos dessa violência na representação política de mulheres? Que iniciativas foram desenvolvidas para enfrentar essa violência? Como se vê, tratam-se de indagações amplas que demandariam uma pesquisa mais aprofundada. Contudo, pretendemos aqui tecer reflexões iniciais com o intuito de construir uma agenda de pesquisas preocupadas com o fenômeno da violência com viés de gênero, já que o Brasil conta com um significativo conjunto de estudos sobre representação política de minorias, mas focam em outros fenômenos e fatores para 
analisar as desigualdades que dificultam ou impedem a representação política desses segmentos.

Nessa direção, temos como objetivo geral analisar o fenômeno da violência contra mulher expresso na institucionalidade política no Brasil, entendido aqui como uma arena. Em termos de objetivos específicos pretendemos (i) identificar ocorrências de violência contra a mulher no Brasil, (ii) refletir a relação de causalidade entre esse tipo de violência e a baixa representatividade das mulheres no parlamento e, por fim, (iii) mapear algumas iniciativas na América Latina que visaram enfrentar violências de gênero na esfera política.

Nosso objeto está inserido no contexto das epistemologias feministas, cuja compreensão corrente é a de que, desde a seleção do objeto até as escolhas metodológicas, não existe neutralidade epistemológica (NARVAZ, 2005). A partir dessa escolha, o presente estudo tem como objeto central a violência contra mulher na política institucional.

Para uma pesquisa que tem como proposta analisar o objeto a partir das vivências e experiências compartilhadas das mulheres, a abordagem utilizada foi a qualitativa, pois cremos que determinados aspectos da experiência humana não são possíveis de serem quantificadas, embora não devam ser desconsiderados dados quantitativos que auxiliem a exploração das questões em tela (MINAYO, 2008).

Inicialmente realizamos um estudo bibliográfico ${ }^{4}$ a partir de referenciais teóricos que contribuíram com o problema apresentado. Também lançamos mão de tipos descritivos, exploratórios e explicativos em nosso estudo, considerando as inferências descritivas que realizamos a partir de casos concretos de violência contra mulheres nas instituições políticas (e fora das instituições, mas ligados umbilicalmente à dinâmica institucional). A dimensão exploratória ocorre com a exploração de um fenômeno ainda pouco investigado no Brasil e a dimensão explicativa se dá nas inferências causais entre a violência política contra a mulher e a sub-representação política desse segmento (LOPES, 2006).

Para a coleta de dados, utilizamos a técnica da pesquisa documental a partir de documentos escritos e audiovisuais ${ }^{5}$. André Cellard observa que “[...] o documento escrito

\footnotetext{
4 “[...] explica um problema a partir de referenciais teóricos publicados em documentos" (CERVO; BERVIAN, 1983).

${ }^{5}$ Entrevistas de TV e Rádio que abordem o tema, gravações da TV Câmara e da TV Senado.
} 
constitui uma fonte extremamente preciosa para todo pesquisador nas ciências sociais" $(2008$, p. 295).

\section{NOTAS SOBRE A VIOLÊNCIA CONTRA MULHER NA ARENA POLÍTICA BRASILEIRA}

As ideias de campo e de habitus de Bourdieu vão contribuir para a compreensão da engenharia política que mantém como minorias as mulheres nos espaços institucionais de poder. Isso porque o habitus $^{6}$ refere-se à interiorização das estruturas e esquemas sociais e culturais no modo como pensamos, sentimos e agimos no cotidiano (BOURDIEU, 1996). As estruturas sociais são demarcadas a partir das relações de poder e das desigualdades entre homens e mulheres. Logo, a ação, o pensamento e o sentimento se dão a partir dos estereótipos de gênero socialmente construídos e internalizados individualmente e coletivamente pelos sujeitos a partir da interação social.

Thiry-Cherques (2016) ao discutir a teoria de Pierre Bourdieu, destaca que os campos são produtos da história. A história é construída pelos sujeitos sociais a partir dos valores e das relações sociais em dada sociedade. Não sendo fixas, podem ser transformadas. É a partir daí que a ideia de campo de Pierre Bourdieu colabora para processos de ruptura com a naturalização que se construiu sobre a posição de inferioridade que impõe às mulheres uma subcidadania ao negar-lhes condições igualitárias de acesso aos espaços de poder.

A ausência das condições reais para que as mulheres exerçam plenamente os direitos políticos é resultado da luta pela dominação do campo político no qual os homens gozam de estruturas (leis, cultura, valores) que os privilegiam, resultando, assim, na violação dos direitos consagrados constitucionalmente na Constituição Federal de 1988 e que tem na sua base o direito à igualdade e liberdade que ainda não se materializaram na vida das mulheres. Como pontuam Miguel e Biroli (2010), são necessários três tipos de recursos para a participação política e para a disputa de cargos públicos: dinheiro, tempo livre e uma rede de contatos. Nos três casos, homens, em geral, possuem vantagens pelos privilégios obtidos pela dominação masculina.

\footnotetext{
${ }^{6}$ Composto por ethos, héxis e eidos.
} 
Historicamente, os movimentos feministas tem denunciado a não efetivação dos direitos previstos na Carta Magna de 88, provocando o Brasil a aderir aos diversos acordos e pactos entre nações com foco na garantia dos direitos das mulheres. A Carta Social das Américas, por exemplo, considera a participação política das mulheres condição indispensável para a democracia em todos os países: “[...] la participación política de las mujeres [...] son condiciones indispensables para el desarrollo y la democracia em todos los países [...]" (OEA, 2012).

O direito de votar e ser votada, resultado direto das reinvidicações das sufragistas no final do Século XIX e começo do XX (PINTO, 2003), representou uma das conquistas políticas mais importantes da luta das mulheres. Contudo, como observam Biroli e Miguel, é bastante pífia a "[...] presença feminina nos espaços de poder após a obtenção desse direito indicou a necessidade de identificar os mecanismos de exclusão mais profundos, além da restrição consignada em lei” (2014, p. 8).

Consideramos que dentre os mecanismos de exclusão das mulheres da política, que resultam nessa presença deficitária, inclui-se a violência contra a mulher na arena política, que no Brasil carece de marcos legais e maiores investigações a respeito. A luta dos movimentos feministas tem concentrado esforços na violência doméstica, o que resultou no seu enfrentamento institucionalizado através de legislações específicas a exemplo da Lei Maria da Penha. Essa concentração de esforços é perfeitamente justificável pelos altos índices de assassinatos ocorridos no interior da vida doméstica.

Porém, precisamos compreender que como desdobramento da violência que ocorre no espaço doméstico, é necessário focar no enfrentamento dessa violência também na esfera pública e na política institucional, considerando que tal ação viola os direitos políticos e impede a representação dos interesses desse segmento, dificultando ainda mais iniciativas de superação das desigualdades entre homens e mulheres em outras esferas da sociedade, inclusive a doméstica.

É necessário também o desenvolvimento de estudos científicos que investiguem os casos de violência contra a mulher na arena política, pois a compreensão mais sofisticada desse fenômeno contribuirá para reflexões mais aprofundadas por diferentes setores e 
instâncias da sociedade e para a elaboração de iniciativas públicas que visem a correção das distorções democráticas.

A discussão de iniciativas coibidoras desse tipo de violência será explorado mais a frente, mas adiantamos o caso da Bolívia, por exemplo, que sancionou em 2012 a Lei 247, que em seu artigo $3^{\circ}$ aponta os objetivos do Estado:

La presente Ley establece los siguientes fines: 1. Eliminar actos, conductas y manifestaciones individuales o colectivas de acoso y violencia política que afecten directa o indirectamente a las mujeres en el ejercicio de funciones político-pública [...].

Nota-se que a lei boliviana preocupa-se em eliminar condutas que representem um obstáculo ao exercício dos direitos políticos das mulheres; e para o enfrentamento a tais práticas adotou medidas políticas e administrativas de caráter pedagógico e não apenas repressivo-punitivo. Em nosso país, casos recentes de violência contra mulheres parlamentares demonstram que "[...] não basta incluir as mulheres e outros grupos marginalizados, sem alterar aspectos institucionais e estruturais das democracias" (BIROLI; MIGUEL, 2010, p. 660).

$\mathrm{Na}$ maioria desses casos parece-nos que o tratamento dado tem sido meramente penal, sem considerar a relação política, cultural e institucional que permeia a prática violadora dos direitos humanos das mulheres. Trazemos como exemplos dessa violência os seguintes casos:

a) Maria do Rosário (PT - RS): Em 9 de dezembro de 2014, a deputada federal Maria do Rosário foi vítima de violência. O deputado Jair Bolsonaro (PSC-RJ) subiu à tribuna e declarou: "Falei que não ia estuprar você porque você não merece. Fica aqui pra ouvir". Jair Bolsonaro já havia, em novembro de 2003, agredido a parlamentar, tendo-a empurrado diante das câmeras da Rede TV no Congresso Nacional.

b) Jandira Feghali (PC do B - RJ): Em 06 de maio de 2015 o presidente do PPS, Roberto Freire, agrediu fisicamente Jandira Feghali, deputada federal pelo PC do B do Rio de Janeiro. Como justificativa, Freire declarou ter agredido a parlamentar por tê-la confundido com um "veado", demonstrando interfaces e cruzamentos entre as violências dirigidas contra as mulheres e contra a população LGBT na política.

c) Dilma Rousseff (Presidenta da República - PT): A Presidenta da República, Dilma Rousseff, foi vítima de violência pela comercialização de adesivos de tamanho $60 \mathrm{~cm} \mathrm{X} 40$ 
cm que sugeriam e incitariam o estupro contra a então presidenta. $\mathrm{O}$ adesivo produzido foi comercializado no sítio de vendas Mercado Livre, sem falar em toda violência decorrente do processo de impeachment que interrompeu seu mandato legitimamente eleito por maioria simples da população.

Os três casos, meramente ilustrativos, demonstram a manifestação desse fenômeno social no Brasil, e apontam para condutas individuais ou coletivas que questionam o lugar da mulher e a subjugam na arena política. Tratam-se de práticas violentas que se expressam como violências física, moral, psicológica e/ou simbólica no exercício de seus mandatos que, diga-se, lhes foram conferidos por uma parcela da população que também é ultrajada com as variadas formas de desqualificação dessas pessoas. Haveria então alguma relação causal entre a prática de tais condutas e o processo de silenciamento das mulheres na política? A hostilidade às mulheres do campo político as afastaria desse espaço? Ou a baixa presença das mulheres na política fortalece a reprodução de práticas sexistas nesse campo?

\section{A RELAÇÃO ENTRE A VIOLÊNCIA POLÍTICA E A SUB-REPRESENTAÇÃo FEMININA}

A Lei de Cotas embora tenha contribuído para a visibilidade da baixa representatividade das mulheres nos espaços institucionais de exercicíco de poder político, mostrou-se insuficiente como mecanismo político-jurídico que assegurasse a correção das distorções da democracia e, portanto, a representação da metade da população brasileira nos espaços de poder.

Autoras como Kim Fridkin Kahn, Kira Sanbonmatsu, Barbara Burrell, Richard Seltzer, Jody Newman e Melissa Voorhees Leughton tem analisado a participação das mulheres na política. Os estudos analisam a influência do sexo nas trajetórias políticas, a influência dos estereótipos na decisão do eleitorado, a relação dos partidos e as particularidades das campanhas políticas femininas. (BIROLI; MIGUEL, 2010).

Biroli e Miguel (2010, p. 662) consideram que nas diversas etapas da vida política “"[...]as mulheres se defrontam com dilemas e empecilhos que lhes são próprias, para além daqueles comuns também aos homens". Consideramos que estaria entre esses dilemas e empecilhos a 
violência perpetradas contra as mulheres que estão na disputa do poder político, seja nos partidos políticos, durante a campanha eleitoral, ao longo do mandato e mesmo após ele.

Na sociedade patriarcal, as mulheres são desautorizadas a falar de política, e quando essa desautorização é questionada, utilizam-se mecanismos violentos para fazer prevalecer a dominação masculina e os privilégios de gênero da nossa sociedade.

Bourdieu (2003, p. 62) observa que “[...] as mulheres são excluídas de todos os lugares públicos (assembleia, mercado), em que se realizam os jogos comumente considerados os mais sérios da existência humana, que são os jogos de honra". Além de excluídas e proibidas de adetrarem em determinados territórios, há uma desvalorização dos espaços imposto as mulheres, a exemplo do espaço doméstico, cujas obrigações atribuídas têm impacto na esfera política.

Consideramos que dentre essas especificidades às quais as mulheres são submetidas no campo político inclua-se a violência estrutural. Miguel (2015) explica que, diferentemente da violência aberta, a violência estrutural é camuflada, naturalizada e invisibilizada, posto que ela está presente permanentemente na ossatura das relações humanas e transborda para a política.

O enfrentamento à violência política, tanto a partir de iniciativas públicas do Movimento Feminista ou do Estado quanto a partir do fomento desse debate na academia, parece ser estratégico para superar a sub-representatividade das mulheres na política no Brasil e no mundo, uma vez que a Comissão Interamericana de Mulheres (CIM) da Organizações dos Estados Americanos (OEA), reconhece que "[...] à medida em que as mulheres ocupam mais espaço nas diversas áreas da arena política [...] têm aumentado as múltiplas manifestações de discriminação e violência que procuram silêncio e limite o seu papel político" (OEA, 2016).

Frente ao reconhecimento que a violência contra as mulheres na arena política limita sua participação, uma vez que as submetem a um processo de silenciamento e afastamento da vida pública, fragilizando a democracia (e seu princípio básico, a igualdade), a OEA, através do Comitê Interamericano da Mulher (CIM) em 2015 “[...] abriu uma nova área de trabalho para o avanço da prevenção, tratamento e punição da violência e assédio contra mulheres na arena política" (OEA, 2016). 
De acordo com dados das eleições para a Câmara Federal em 2014, dos 513 assentos parlamentares apenas 52 foram ocupados por deputadas federais. Isso representa um percentual de 9,9\% daquela Casa Legislativa (TRE, 2014).

Observa-se que passados mais de 20 anos da criação de legislações que definem cotas para as mulheres na política (Lei 9.100/95 e Lei 9.504/1997), não conseguimos avançar na garantia da igualdade de acesso das mulheres aos espaços institucionalizados de poder. Isso porque, como observou Miguel (2000, p. 91), o arcabouço jurídico que versa sobre cotas para as mulheres no Brasil é tímido, pois, não incide sobre as eleições majoritárias e no caso das proporcionais “[...] não há reserva de cadeiras no Parlamento, mas apenas de vagas de candidaturas". Ademais, os partidos investem pouco nas candidaturas de mulheres, que sem o amplo apoio partidário, sem uma rede de contatos ampla e muitas vezes sem o apoio da família, ficam expostas as mais diversas manifestações de violências.

Em 19 de março de 2014, o então Presidente do Tribunal Superior Eleitoral, o Ministro Marco Aurélio Mello, admitiu que no Brasil, as coligações partidárias, inscrevem "mulheres-laranja", ou seja, mulheres são inscritas nas chapas para os cargos proporcionais (vereadoras, deputadas e senadoras), mas sem o devido investimento nas campanhas. Assim, os partidos burlam a Lei, pois a cumprem formalmente, mas não materialmente. Com isso, as mulheres permanecem com baixa representatividade na política (TSE, 2014).

A expressão mulheres-laranjas, é utilizada em duas situações: (i) para referir-se a candidaturas de mulheres que não se representam, ou seja, não representam um projeto político próprio (e aqui nem estamos falando em um ideal projeto feminista), mas sim interesses de um homem que por algum motivo não pode candidatar-se, a exemplo de Anderson Adauto (PP), que, impedido de candidatar-se a Prefeitura de Uberaba/MG, lançou a candidatura da esposa Ângela Mayrink (PP). (ii) O termo é ainda utilizado para referir-se a candidaturas fantasmas, aquelas em que a candidatura das mulheres são inscritas pelo partido político apenas para cumprir uma formalidade legal. por vezes nem a mulher sabe que seu nome foi inserido na lista (!). Em 2016, o TSE apurou que 16.131 candidaturas não receberam nenhum voto, dessas candituras, 14.417 são de mulheres e apenas 1.714 são de homens (TSE, 2016). 
Grossi e Malheiros Miguel (2001) refletem, a partir das falas das participantes no seminário "Mulheres na Política, Mulheres no Poder", realizada pela Câmara de Deputados em 2000, as desigualdades de gênero no campo político. As autoras chamam atenção para relatos de experiência que constituem empecilhos para a participação das mulheres nos espaços de poder. Um desses empecilhos que identificamos a partir das falas acionadas no texto refere-se à falta de apoio familiar:

Tive a coragem de desmanchar um casamento há algum tempo e outro mais recentemente (risos). Não me importei com as consequências por entender que meus direitos são iguais aos dos homens [...] A mulher na poltica tem que ter muito idealismo [...] deve saber que vai deixar filhos e família, vai perder o marido, terá que arranjar outro, que, provavelmente, perderá também. Essa é verdade (Prefeita Wilma de Farias PSB/Natal/RN).

Sem apoio familiar, sem investimento dos partidos, as mulheres que se envolvem com a política sofrem publicamente ataques violentos especialmente relacionados a sua sexualidade. Em 2014, Marília Arraes, Vereadora de Recife/PE e neta de Miguel Arraes, após um racha no clã pernambucano, manifestou apoio ao candidato ao Governo de Pernambuco Armando Monteiro (PTB) enquanto a família Arraes e o PSB de Pernambuco tinham como candidato ao governo estadual Paulo Câmara (PSB). Após a sua escolha pela independência política, Marília foi vítima de diversos ataques a sua honra e a sua condição de mulher.

Em 06 de agosto de 2014, jornais e blogs políticos do estado inteiro noticiaram que pessoas do/no comitê de campanha do PSB batizaram uma cadela com o nome de Marília Arraes, embora, registre-se, a Coordenação da Campanha de Paulo Câmara tenha negado a informação.

No dia seguinte, os ataques a vereadora ocorreram por meio de pichações nos muros de diversos imóveis da cidade do Recife.

Uma das pichações remete a vida conjugal de Marília, apresentando a mensagem "Marília Arrais Gaiera”. Gaia, na linguagem pernambucana, significa traição e infidelidade demonstrando a tentativa de desqualificação da Vereadora em análise. Já em outra pichação, são os atributos físicos da vereadora que são acionados na frase "Marilia Arrais Traidora e Gorda", visando, assim, atacar o corpo da parlamentar por intermédio da gordofobia, algo difícil de ser imaginado no caso de um eventual xingamento a um político homem. 


\section{Revista
Debates Insubmissos}

Observe-se que mesmo sendo de uma família tradicional na política pernambucana, a vereadora, atualmente filiada ao Partido dos Trabalhadores, é vítima constante de violência política ainda que esta não ocorra nas instituições formais da representação política como o parlamento, por exemplo. Com efeito, os ataques ocorreram fora dos espaços institucionais, mas almejaram prejudicá-la nessa arena.

Também em 2014, a deputada estadual Manuela D’ávila (PCdoB) após sofrer ameaça de estupro, acionou a Procuradoria Geral da República. Em seguida, declarou no seu perfil do Facebook:

Boa noite! Estou aqui na sessão na Câmara votando uma Medida Provisória e queria compartilhar com vocês a decisão que tomei de ir a Procuradoria Geral da República pedir investigação de um perfil de twitter que me ameaça repetidas vezes de estupro. É cansativo, perdemos energia... Mas precisamos mostrar para essa turma que a internet não é terra de ninguém. Que as ameaças aqui também tem consequências. Lutar por uma cultura de paz, mais solidária é, muitas vezes, duro, cansativo... Mas vale a pena. Boa noite!

A fala da deputada nos mostra que a violência sofrida interfere na disposição e no cotidiano do trabalho político. Algumas mulheres resignificam a violação transformando a dor de serem vítimas em agendas de luta pelo fím da violência. Outras, ao "perderem energia" acabam desistindo e se afastando da política.

Desse modo, é possível verificar que as violências sofridas pelas mulheres na esfera política são estruturais, simbólicas e naturalizadas, mas também são diretas (psicológica, moral e física) e abertas. As análises sobre ambos os casos nos indicam também que, de maneira estratégica, os ataques se manifestam foram das instituições liberais, mas estão diretamente vinculados a elas, como os ataques virtuais nas redes sociais, por exemplo. Esse é um tipo de suporte mais ou menos novo em que diversas parlamentares tem sido ameaçadas, ofendidas, difamadas e injuriadas em face do seu gênero. É válido ainda ressaltar que figuras políticas LGBT também sofrem fenômenos semelhantes, dificultando a sua inserção na vida política e impondo barreiras à representação (CARTACAPITAL, 2017).

Apesar de compreendermos que a exclusão política nunca é determinada por uma única variável, é notória a relação de causalidade entre a violência e a sub-representação política de mulheres (e outros segmentos vulneráveis) no cenário político nacional, afinal, a 
hostilidade e a agressividade dirigidas as mulheres, dificultam, afastam e impedem a sua entrada em um terreno belicoso e ameaçador, sobretudo quando observamos a impunidade e a naturalidade com que tal fenômeno é tratado pelas autoridades republicanas. Pensando nas alternativas de enfrentamento e superação de tal realidade, passamos a discutir experiências significativas realizadas em alguns países próximos ao Brasil.

\section{EXPERIÊNCIAS DE ENFRENTAMENTO À VIOLÊNCIA CONTRA MULHER NA POLÍTICA INSTITUCIONAL}

Na América Latina, países como a Bolívia e o Equador tem desenvolvido experiências importantes no enfrentamento a esse tipo de violência contra a mulher. Já em um plano mais amplo, para além da América do Sul, esse enfrentamento vem sendo visibilizado, pautado e agendado especialmente pela ONU que tem apoiado diversas iniciativas. Dentre elas, destacamos aquelas desenvolvidas na Costa Rica.

A Costa Rica partiu de um diagnóstico que apontou os principais obstáculos para a participação política das mulheres, sendo destacado dentre eles:

1. A Existência de um marco cultural e de valores que substimam a capacidade de desempenho das mulheres na política (GARCIA, 2010).

2. A Dicotomia entre o público e o privado:

El papel que desempeñan las mujeres en las familias, su rol de cuidadoras, el uso de su tiempo, la exclusividad de la responsabilidad familiar (que inclusive las excluye de los mecanismos informales de toma de decisiones) son aspectos importantes de las condiciones que les permiten (o no) a las mujeres un desempeño en el ámbito público. El ejercicio de la democracia implica la libertad del sujeto; si las mujeres no cuentan con autonomía, difícilmente pueden hacer visible su identidad en el espacio público y por ende, mucho menos incorporar sus temas e intereses o liderar acciones en ese sentido (GARCIA, 2010).

De modo que sem considerar que tais espaços se relacionam e se retroalimentam não é possível enfrentar a problemática.

3. A predileção por candidaturas de homens, sujeitos que ocupam os espaços decisórios nos partidos, fazendo com que as habilidades das mulheres, construídas a partir de 


\section{Debates Insubmissos}

Revista

preconceitos e esteriótipos de gênero, sejam vistas como pouco competitivas (GARCIA, 2010).

O estudo escutou 57 mulheres das quais $40 \%$ relatam a violência, manifestada através da rejeição, discriminação e hostilidade, como fatores que obstam a participação política:

[...] las 57 entrevistadas ubican al "rechazo, discriminación y hostilidad" como el factor más limitante $(40 \%$ de las respuestas), seguido por la inexperiencia y desconocimiento ocasionado por la poca formación política (24\%), y las dificultades que plantea articular la política con las responsabilidades en el ámbito familiar (14\%) (GARCIA, 2010).

Em face desse cenário, a Costa Rica aderiu ao Consenso de Quinto (2007), através do qual comprometeu-se em:

Adoptar medidas legislativas y reformas institucionales para prevenir, sancionar y erradicar el acoso político y administrativo contra las mujeres que acceden a los puestos de decisión por vía electoral o por designación, tanto en el nivel nacional como local, así como en los partidos y movimientos políticos (CONSENSO DE QUITO, 2007).

Ocorre que o Brasil enfrentou tais questões através do fortalecimento da participação das mulheres nos instrumentos da democracia participativa, tais como as Conferências, Conselhos, Orçamentos Participativos, etc. (SILVA, 2012). No entanto, não se incidiu politicamente e juridicamente no enfrentamento às violencias sofridas por mulheres ao disputarem tais espaços de poder, o que de certo modo, ocorre porque no país, tal temática é invísivel e pouco discutida, sobretudo pela grande mídia que representa os principais meios de produção simbólica através da agenda que fomenta na opinião pública.

Tal temática tem tido maior espaço na pauta política e nos estudos epistemológicos no Equador e na Bolívia, através da Asociación de Concejalas de Bolivia (ACOBOL) y la Asociación de Mujeres Municipalistas de Ecuador (AMUME) (GARCIA, 2010).

Na Costa Rica, o enfrentamento a tal problema ocorreu com o apoio do Programa de las Naciones Unidas para los Asentamientos Humanos (UN-HABITAT) e do Projeto de Fortalecimiento Municipal y Descentralización (FOMUDE) (GARCIA, 2010). A iniciativa em Costa Rica foi então no sentido de identificar e sistemaizar como esse vivência hostil obsta o pleno exercício dos direitos políticos das mulheres, partindo da escuta de figuras femininas que exercem ou disputam cargos no poder local (GARCIA, 2010). 


\section{Revista \\ Debates Insubmissos}

Assim, entre as principais práticas violentas segundo Escalante y Méndez (Apud GARCIA, 2010), estão aquelas que "[...] afectan e inhiben el derecho a la participación de las mujeres, así como su desempeño eficaz en los cargos municipales[...]" dentre as quais se destacam:

1. Intimidação, discriminação e subordinação pelo fato de serem mulheres.

2. Desqualificação, estigma, manipulação e perseguição e mesmo assédio sexual.

3. Pressões para tomarem decisões contra a sua vontade.

4. Pressão de partidos políticos para forçá-las a renunciar.

5. Pressão psicológica e até mesmo violência física.

6. Fofocas, propagação e rumores, desrespeito.

7. Coerção para realizar ações ou tomar decisões sem discussão e opinião, em troca de apoio para continuarem a atuar politicamente.

Observe-se que várias das violências sofridas pelas mulheres qua atuam na política em Costa Rica, assemelha-se aos casos ocorridos no Brasil e apresentados nos tópicos anteriores à título de ilustração.

Se na Costa Rica o enfrentamento a violência contra mulher na arena política iniciase com a identificação e sistematização dessa trágica experiência das mulheres, o que é fundamental para visibilização política do fenômeno, na Bolívia, esse enfrentamento ocorre através de mudanças na legislação. Assim, a Constituição de 2009 em seu artigo 15 enfrenta todas as formas de violência contra mulher incluindo aquelas sofridas no âmbito público (GARCIA, 2010).

Também na Bolívia, a Lei de Regime Eleitoral de 2010, reconhece a violência na arena política como delito eleitoral:

Artículo 238 (DELITOS ELECTORALES). Constituyen delitos electorales los siguientes actos y omisiones:

[...] Acoso Político. La persona que hostigue a una candidata o candidato, durante o después de un proceso electoral, con el objeto de obtener contra su voluntad la renuncia a su postulación o a su cargo, será sancionada con pena privativa de libertad de dos (2) a cinco (5) años.

Como já destacamos, em 2012 a Bolívia promulgou a Lei 247 que conceitua e define os crimes de assédio e a violência política contra as mulheres e em 2013 a Lei 348 seguiu a 
Constituição do país e inseriu a violência política dentre as demais violências contra as mulheres a serem enfrentadas. Nesse sentido, os marcos legais da Bolívia conceituam, tipificam e impõe ao Estado a responsabilidade para conter tal problema, reconhecendo o fenômeno.

Outros países também desenvolveram experiências de enfrentamento à violência contra mulher a partir da constituição de marcos legais. Cite-se o México no ano de 2013 através da "Ley General de Acceso de las Mujeres a una Vida Libre de Violencia" e no “Código Federal de Instituciones y Procedimientos Electorales". Também o Peru em 2016 trata do problema através do decreto n. 8 (BIROLI, 2016).

Biroli (2016) destaca a invisbilidade do tema no Brasil e aponta que seguir o exemplo dos demais países da América Latina realizando mudanças legais pode ser uma possibilidade de ruptura com tal fenômeno:

Nos debates correntes, assim como nas publicações acadêmicas e feministas, a noção de violência política contra as mulheres raramente tem sido mobilizada no país. Penso em duas hipóteses para explicar essa ausência. A primeira é que esse tipo de violência seja pouco relevante ou mesmo inexistente por aqui. Eu apostaria em uma segunda hipótese: a violência contra as mulheres na política brasileira está naturalizada e, por isso, não é reconhecida, explicitada e discutida. Caso ela faça sentido, esse é um tema com o qual precisamos lidar.

$[\ldots]$

Parece-me que faz sentido partir das leis já aprovadas em outros países latino-americanos, mas também dos indícios que temos de como vem se dando a dinâmica da violência política no Brasil. Mulheres políticas, que a vivenciam, também poderiam nos ajudar a perceber melhor como ela se dá no caso brasileiro (BIROLI, 2016) ${ }^{7}$.

Nos filiamos, assim, a Biroli (2016) na compreensão de que a ausência de marcos legais que tipifiquem a violência contra mulher na política institucional em âmbito interno representa o descompromisso do Estado com tal agenda, o que acaba gerando omissões por parte do poder público no enfrentamento de tal problema social, restando aos movimentos, ativistas e vítimas realizarem iniciativas de enfrentamento no campo político, denunciando tais violências, problemantizando no campo acadêmico estudos que identiquem e sistematizem tais fenômenos e, numa conjuntura extremamente dificil como a que vivemos,

\footnotetext{
${ }^{7}$ Artigo disponível na Internet, em texto corrido e portanto sem paginação.
} 


\section{Debates Insubmissos}

Revista

articulem parlamentares que foram/são vítimas na formulação de projetos de lei que conceituem e tipifiquem tal violência.

\section{CONSIDERAÇÕES FINAIS}

O estudo realizado confirmou as hipóteses inicialmente levantadas: A) uma das formas de expressão da dominação masculina é a violência contra as mulheres no campo político; B) a violência contra mulher na arena política é uma variável que contribui para a baixa presença das mulheres nos espaços políticos; e C) no Brasil, esse fenômeno é ainda invísivel nos espaços institucionais dos poderes públicos e pouco debatido na academia e nos movimentos socais.

Ao retomarmos a primeira questão-problema proposta para análise (de que modo a violência contra a mulher se expressa na política institucional?), a pesquisa bibliográfica e documental realizada permitiu identificar que as ocorrências de violência contra a mulher no Brasil, se manifesta através de xigamentos que exploram a sexualidade e características físicas da mulher, ameaças especialmente de estupro e violência física o que restou constatado através dos casos envolvendo a Presidenta da República deposta do cargo Dilma Rousseff, as Deputadas Federais Maria do Rosário e Jandira Feghali, da Deputada Estadual Manuela D’ávila e da Vereadora Marília Arraes.

A segunda questão para análise foi: Quais os efeitos dessa violência na representação política de mulheres? Consideramos que a violência contra mulher na arena política acaba contribuindo para a baixa representatividade das mulheres nos espaços de poder no Brasil e que se as bases da violência não forem desestruturadas, dificilmente resolveremos o problema da democracia que recentemente impediu a primeira mulher eleita Presidenta da nossa história republicana de governar. Isso porque, o efeito decorrente da banalização e naturalização das violências sofridas por mulheres durante o processo eleitoral ou no exercicio do mandato, acaba por desestimular novas candidaturas. Dedicar-se a atividade política é perigoso para as mulheres no Brasil. As políticas de cotas torna-se insuficiente para resolver o problema da falta de representação política das mulheres, é necessário garantir outros mecanismos que 
assegure condições reais para a participação das mulheres e dentre esse mecanismos deve-se incluir o enfrentamento a violência.

A última questão, era: Que iniciativas foram desenvolvidas para enfrentar essa violência? No Brasil, nenhuma iniciativa até então foi desenvolvida, mas, foi possível a partir do estudo de experiência de enfrentamento em países da América Latina, visualizar que especialmente na Bolívia, Peru e México, o enfrentamento ocorreu a partir da instituição de marcos legais e refletir que a ausência desses marcos no Brasil indica a necessidade de, conforme a Costa Rica, iniciarmos o enfrentamento com a realização de estudos que identifiquem e sistemaizem tal fenômeno no país (investigando não só as instituições políticas de abrangência nacional, como estaduais e municipais).

$\mathrm{Na}$ sociedade e na democracia brasileiras homens e mulheres ainda não têm as mesmas condições e recursos para exercerem seus direitos políticos. Frente a essa realidade, o estudo buscou contribuir para o fomento de uma agenda de pesquisas na área, uma vez que são poucas as produções científicas que abordam a relação entre violência aberta na política institucional e participação política das mulheres no Brasil. Dessa maneira, esperamos que os breves apontamentos epistemológicos aqui apresentados colaborem de alguma forma para a superação da violação de direitos políticos das mulheres e para um debate mais amplo da necessidade da criação de mecanismos e instrumentos que assegurem a igualdade no acesso aos espaços de poder político e na consolidação da combalida democracia brasileira.

\section{REFERÊNCIAS}

BARDIN, Laurence. 2001. Análise de Conteúdo. Lisboa: Relógio D’água Editores.

BIROLI, Flávia. O público e o privado. In: BIROLI, F.; MIGUEL, L. F. Feminismo e política. São Paulo: Boitempo, 2014.

. (2016). Violência política contra as mulheres. Disponível em: https://blogdaboitempo.com.br/2016/08/12/violencia-politica-contra-as-mulheres/. Acesso em: 02 out. 2017.

; MIGUEL, Luis Felipe. 2010. Práticas de gênero e carreiras políticas: vertentes explicativas. Estudos Feministas, Florianópolis, v. 18, n. 3, pp. 653-679, setembrodezembro. 
BLOGDOJAMILDO. Muros do Recife aparecem pichados com agressões contra Marília Arraes. Disponível em http://blogs.ne10.uol.com.br/jamildo/2014/10/23/muros-recifeaparecem-pichados-com-agressoes-contra-marilia-arraes/. Acesso em: 02 out. 2017.

BOLÍVIA. 2012. Ley n⿳ 243/2012. Disponível em:

http://www.ine.gob.bo/indicadoresddhh/archivos/viole/nal/Ley\%20N\%20243.pdf. Acesso em: 02 out. 2017.

BONI, Valdete; QUARESMA, Silvía Jurema. 2005. Aprendendo a entrevistar: como fazer entrevistas em Ciência Sociais. Em Tese, Florianópolis, v. 2, n. 1, pp. 68-80, janeiro-julho.

BOURDIEU, Pierre. Razões práticas: sobre a teoria da ação. São Paulo: Papirus, 1996.

A dominação masculina. Rio de Janeiro: Bertrand Brasil, 2003.

BRASIL, TSE. (2014). Eleições 2014: número de deputadas federais cresce 13,33\% em relação a 2010. Disponível em: http://www.tse.jus.br/imprensa/noticiastse/2014/Outubro/eleicoes-2014-numero-de-deputadas-federais-cresce-13-33-em-relacao-a2010. Acesso em: 02 out. 2017.

Presidente do TSE diz que partidos usam 'mulheres-laranja' para

cumprir cota. Disponível em:

http://www.em.com.br/app/noticia/politica/2014/03/19/interna_politica,509672/presidente-dotse-diz-que-partidos-usam-mulheres-laranja-para-comprir-cota.shtml. Acesso em: 02 out. 2017.

Mais de 16 mil candidatos tiveram votação zerada nas Eleições 2016. Disponível em: http://www.tse.jus.br/imprensa/noticias-tse/2016/Novembro/mais-de-16-milcandidatos-tiveram-votacao-zerada-nas-eleicoes-2016. Acesso em: 02 out. 2017.

BRASIL. Lei 9.504/1997. Disponível em:

https://www.planalto.gov.br/ccivil_03/Leis/L9504.htm. Acesso em: 02 out. 2017.

BRASIL247.Maria do Rosário: 'Fui Agredida Como Mulher e Parlamentar'. Disponível em: $\quad$ http://www.brasil247.com/pt/247/rs247/163262/Maria-do-Ros\%C3\%A1rio-'Fuiagredida-como-mulher-como-parlamentar-e-m\%C3\%A3e'.htm. Acesso em: 02 out. 2017.

CELLARD, André. A análise documental. In: POUPART, J. et al. A pesquisa qualitativa: enfoques epistemológicos e metodológicos. Petrópolis: Vozes, 2008.

CERVO, Amado Luiz.; BERVIAN, Pedro Alcino. Metodologia científica: para uso de estudantes universitários. 3. ed. São Paulo: McGraw-Hill do Brasil, 1983.

CIRNE, Julio. Em comitê oficial, socialistas batizam cadela em homenagem a Marília Arraes. Vereadora protesta na Câmara Municipal do Recife. Disponível em: http://blogs.ne10.uol.com.br/jamildo/2014/08/06/em-comite-oficial-socialistas-batizam- 
cadela-vira-lata-com-nome-de-marilia-arraes-vereadora-protesta-na-camara-municipal-dorecife/. Acesso em: 02 out. 2017.

FEITOSA, Cleyton. Ambição política é a primeira barreira à inclusão política de LGBT's. Disponível em http://justificando.cartacapital.com.br/2017/07/31/ambicao-politicae-primeira-barreira-inclusao-politica-de-lgbts/. Acesso em: 04 out. 2017.

FOUCAULT, Michel. 2006. A ordem do discurso. 13. ed. São Paulo: Loiola.

GROSSI, Míriam Pillar. MIGUEL, Sônia Malheiros. 2001. Transformando a diferença: as mulheres na política. Estudos Feministas, Florianópolis, v. 9, n. 1, pp. 167-206.

LEIAJA. Marília Arraes é Chamada de Traidora em Pichações Recife. Disponível em: http://www.leiaja.com/politica/2014/10/23/marilia-arraes-e-chamada-de-traidora-empichacoes-recife/. Acesso em: 02 out. 2017.

LOPES, Jorge. O fazer do trabalho científico em ciências sociais aplicadas. Recife: Editora Universitária da UFPE, 2006.

MATOS, Marlise; PARADIS, Clarisse Goulart. Desafios à despatriarcalização do Estado brasileiro. Cadernos Pagu, Campinas, pp. 57-118, julho-dezembro, 2014.

MIGUEL, Luis Felipe. Teoria política feminista e liberalismo: o caso das cotas de representação. Revista Brasileira de Ciências Sociais, v. 15, n. 44, pp. 91-102, outubro, 2000 .

MIGUEL, Luis Felipe. O Feminismo e a política. In: BIROLI, F.; MIGUEL, L. F. Feminismo e política. São Paulo: Boitempo, 2014.

MINAYO, Maria Cecília de Souza. O desafio do conhecimento: pesquisa qualitativa em saúde. 11 ed. São Paulo: Hucitec, 2008.

NARVAZ, Martha Giudice. Submissão e resistência: explodindo o discurso patriarcal da dominação feminina. Porto Alegre. Dissertação (Mestrado em Psicologia). Universidade Federal do Rio Grande do Sul, 2005.

OEA. (2012). Carta Social das Américas. Disponível em: https://oas.org/consejo/sp/docs/AG05806P05.doc. Acesso em: 02 out. 2017.

OEA. Violência e assédio contra as mulheres na arena política. Disponível em: http://www.oas.org/es/cim/violenciapolitica.asp. Acesso em: 02 out. 2017.

PINTO, Celi Regina Jardim. Uma história do feminismo no Brasil. São Paulo: Editora Fundação Perseu Abramo, 2003.

PRAGMATIMOSPOLÍTICO. Adesivos de Dilma Com Pernas Abertas São a Nova Moda Contra A Presidente. Disponível em: 
http://www.pragmatismopolitico.com.br/2015/07/adesivos-de-dilma-com-pernas-abertas-saoa-nova-moda-contra-a-presidente.html. Acesso em: 02 out. 2017.

Deputada Jandira Feghali é Agredida em Dia de Vergonha na Câmara dos Deputados. Disponível em: http://www.pragmatismopolitico.com.br/2015/05/deputadajandira-feghali-e-agredida-em-dia-de-vergonha-na-camara-dos-deputados.html. Acesso em: 02 out. 2017.

SAFFIOTI, Heleieth. A mulher na sociedade de classes: mito e realidade. 3 ed. São Paulo: Expressão Popular, 2013.

SARDINHA, Edson. Manuela D'Ávila denúncia à PGR ter sofrido ameaças de estupro. Disponível em: http://congressoemfoco.uol.com.br/noticias/manuela-davila-denuncia-a-pgrter-sofrido-ameacas-de-estupro/. Acesso em: 02 out. 2017.

SCOTT, Joan. (1995). Gênero: uma categoria útil para análise histórica. Disponível em: moodle.stoa.usp.br/mod/resource/view.php?id=39565. Acesso em: 02 out. 2017.

SILVA, Louise Caroline Santos de Lima e. Conferências nacionais de políticas públicas e democracia participativa: conferências de políticas para as mulheres e decisões governamentais no período Lula (2003-2010). Recife. Dissertação (Mestrado em Ciência Política). Universidade Federal de Pernambuco, 2012.

THIRY-CHERQUES, Hermano Roberto. Pierre Bourdieu: a teoria na prática. Revista de Administração Pública, Rio de Janeiro, v. 40, n. 1, pp. 27-55, janeiro-fevereiro, 2006.

Submetido em: 20/06/2018

Aprovado em: 15/08/2018 